\title{
Nocturnal hypothermia and its energetic significance for small birds living in the arctic and subarctic regions. A review
}

\author{
RANDI EIDSMO REINERTSEN
}

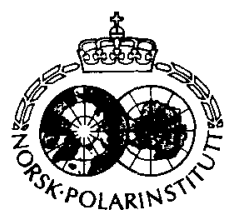

\begin{abstract}
Reinertsen, R. E. 1983: Nocturnal hypothermia and its energetic significance for small birds living in the arctic and subarctic regions. A review. Polar Research 1 n.s., 269-284.

Nocturnal hypothermia is demonstrated in a number of small northern birds. These birds utilize hypothermia among other energy-saving mechanisms and lower the body temperature by some $10^{\circ} \mathrm{C}$. In most bird species hypothermia is utilized only in conjunction with a state of inanition. However, hypothermia has also been demonstrated in birds with satisfactory feeding conditions and body weight. For none of the small northern birds utilizing nocturnal hypothermia, is inanition necessary for the induction of a state of hypothermia. A seasonal effect on the hypothermic response has been demonstrated for two species of tits, the black-capped chickadee Parus atricapillus and the willow tit Parus montanus, and also for an Andean hummingbird. The depth of hypothermia achieved significantly and linearly was correlated with the ambient temperature for the same two species of tits. By the use of nocturnal hypothermia, birds living in temperate zones can save as much as $75 \%$ of their energetic costs, compared with their energy consumption at normal body temperature. The reduction in the nightly expenditure of energy is considerable also in small-sized arctic and subarctic birds that utilize nocturnal hypothermia. The saving of energetic costs may easily represent the margin between life and death for such small birds living under the combined stresses of hunger, cold and long nights.
\end{abstract}

Randi Eidsmo Reinertsen, Department of Zoology, University of Trondheim, N-7055 Dragvoll, Norway.

\section{Introduction}

Bird species remaining as permanent residents in the arctic and subarctic regions are faced with a challenging survival problem during the winter months. Because of their dependence on the visual sense, birds are predominantly daytime feeders, and the shortness of daylight in winter reduces the time available for foraging in a season when food supplies are most limited.

It is at night, during the enforced fasting period, that an energy crisis for body heat maintenance is likely to occur. The nocturnal energetic cost will be a function of such environmental factors as length of the night and the roosting microclimate (ambient temperature, wind velocity, radiative, conductive and evaporative heat losses).

The shortness of the days in winter implies a nocturnal fasting period of very long duration. North of the Arctic Circle, the sun never rises above the horizon in wintertime. The duration of this sunless period depends on the local latitude. Despite these sunless days in midwinter, however, there is a long period of twilight, which apparently suffices for such daylight-dependent birds to find their food. The 24 -hour cycle, char- acterized by alternating feeding and fasting phases, necessitates that enough food be found in daytime to cover both the maintenance costs during the day and an accumulation of reserve energy supplies to meet the energetic outlay during the following night. The smallest birds living at high latitudes may have special difficulties fulfilling this latter demand; the relationship between the birds' capacity for energy storage and their rate of energy consumption by day and night indicates the shortest time which may elapse before depletion of the energy stores occurs and a consequent energy crisis arises.

The ambient temperature is perhaps the most easily measured environmental variable that can influence the rate of energy expenditure. The ambient temperature acts primarily because of the body heat lost through radiation, convection and conduction, and depends on the difference between the body temperature and the ambient temperature (e.g. Kleiber 1961, 1972). At low ambient temperatures a small-sized bird must add relatively more to its basal energy requirement than a large-sized bird. In the arctic and subarctic regions inhabited by small birds, the air temperature during wintertime may vary between 
$-50^{\circ} \mathrm{C}$ and $+10^{\circ} \mathrm{C}$. The normal mean body temperature $\left(T_{b}\right)$ of a resting bird is about $40 \pm 1.5^{\circ} \mathrm{C}$ (Calder \& King 1974). Homeothermic (and normothermic) birds are thus confronted with overcoming a temperature difference $\left(T_{b}-T_{a}\right)$ of 30 to $90^{\circ} \mathrm{C}$. To maintain a constant body temperature, the rate of heat production must equal the rate of heat loss.

The ways in which small birds adjust to the environmental problems encountered in arctic and subarctic regions during the wintertime are discussed under the following main headings:

1. Thermoregulatory responses to cold, the emphasis being placed on nocturnal hypothermia and its relevance for small birds. A comprehensive table is presented, which summarizes the published observations up to 1982 on nocturnal hypothermia in birds.

2. The availabile studies of hypothermia in small-sized birds in northern latitudes are reviewed.

3. The energetic significance of such nocturnal hypothermia is discussed.

\section{Thermoregulatory responses to cold}

To cope with such a situation in the long term, a variety of general strategies have been developed. The heat conservation mechanisms include microhabitat selection, and postural, physical and physiological adaptations.

\section{Microclimate}

Very little information is available about the nocturnal behaviour of birds during cold weather. Own observations on various species of tits, both free-living (at $63^{\circ} \mathrm{N}$ ) and in captivity, indicate that the great tit Parus major (18 g) and the blue tit $P$. caeruleus $(11 \mathrm{~g})$ seek shelter in nest boxes during cold nights in winter, whereas the willow tit $P$. montanus $(10-12 \mathrm{~g})$ in captivity very seldom seeks any kind of shelter. Free-living willow tits have not been observed in nest boxes even during the coldest nights in winter, and probably spend the night in the open. Ptarmigans Lagopus mutus and snow buntings Plectrophenox nivalis avoid the cold at night by seeking shelter under the snow-cover (Irving 1960). Huddling behaviour by small mammals is commonly observed, and has also been observed for birds. However, the exact situation in which most bird species pass the night is unknown, and the available information about the microclimate of the roosting sites is so far insufficient to indicate the extent of the thermal protection afforded by these habitats.

\section{Postural adjustments}

Since heat loss mainly takes place from the body surface, any postural adjustments that help to lower the surface-to-volume ratio are important heat conservation mechanisms. These adjustments include fluffing-up (Steen 1958) and retraction of the extremities. Since the eye region and the bill are sites of rapid heat loss (Hill et al. 1980 ), postural adjustment that involves protection of the head appears to be of special thermal significance. Tits protect these regions by tucking their heads beneath the feathers on their backs (Veghte \& Herreid 1965; Steen 1958).

\section{Physiological adaptations}

A series of papers listed in a review by Dawson \& Hudson (1970) indicate that vasomotor and circulatory modifications are of minor significance in reducing heat loss of surfaces covered by feathers. However, vascular adjustments which facilitate a countercurrent exchange of heat in the legs are of considerable importance, because the temperature difference between the exposed surfaces and the environment are thereby minimized at low ambient temperatures.

Feathers provide a very effective heat insulation in relation to their weight, and the plumage of resident birds in northern climates tends to be relatively heavier than that of their migratory counterparts (Turcek 1966; Irving 1960). The black-capped chickadee's plumage is also heavier in winter than in summer (Chaplin 1974). Furthermore, the insulatory capacity of the plumage can be considerably increased by ptiloerection of down and feathers. This has been nicely demonstrated for the black-capped chickadee by Hill et al. (1980).

\section{Nocturnal hypothermia}

Even when all the above-mentioned mechanisms for heat conservation are utilized, the energy drain of normothermia may be potentially lethal under the environmental nightly conditions prevailing in arctic regions in the winter. In such situations it may also be necessary for birds to 
develop a capacity for regulated hypothermia. Among poikilotherms the most common method of lowering the metabolic rate is reducing of the body temperature. Among mammals, seasonal hibernation is common among moderately sized species and is associated with a seasonal minimum in food availability and the onset of low air temperatures (Fisher \& Mannery 1967). Torpor, on a daily basis, is recorded for several small mammalian species, and appears to be related to food availability and energy expenditure (Tucker 1966; Brown \& Bartholomew 1969; French 1976). The terms hypothermia, torpor, and hibernation are used according to the definitions given by Calder \& King (1974):

Hypothermia. - Body temperature below the normal (normothermia) for resting birds. This may be only a few degrees (e.g. $T_{b}=34^{\circ} \mathrm{C}$ in the turkey vulture, Heath 1962) or profound $\left(\mathrm{T}_{\mathrm{b}}=8.8^{\circ} \mathrm{C}\right.$ in the Anna's Hummingbird, Bartholomew et al. 1967)

Torpor. - Profound hypothermia, in which heart, respiratory, and metabolic rates are greatly depressed, coordination is essentially absent, and response to external stimulation diminished or absent (Jaeger 1948, 1949; Bartholomew et al. 1957; Pearson 1960).

Hibernation. - A state of torpor throughout a long period of food shortage in the winter.

Diurnal cycles of normothermic $T_{b}$ are wellknown (for reviews, see Aschoff \& Pohl 1970a, b; Dawson \& Hudson 1970; Binkley et al. 1971), and a slight lowering of the body temperature in the thermoneutral zone during the night is not considered here as proper nocturnal hypothermia.

When a bird maintains a constant body temperature, the rate of heat production $\left(\mathrm{H}_{\mathrm{m}}\right)$ must equal the rate of heat loss $\left(\mathrm{H}_{\mathrm{dl}}\right)$. According to Scholander et al. (1950), the heat loss is proportional to the temperature difference between that of the bird's body and of its environment (eq 1):

$\dot{\mathrm{H}}_{\mathrm{m}}-\dot{\mathrm{H}}_{\mathrm{e}}=\dot{\mathrm{H}}_{\mathrm{dl}}=\mathrm{h}\left(\mathrm{T}_{\mathrm{b}}-\mathrm{T}_{\mathrm{a}}\right)$

where $h$ is the 'heat transfer coefficient' or 'conductance'. From this, it follows that with given $\mathrm{T}_{\mathrm{a}}$ and conductance the only component that can be varied, so as to extend the endurance time of the fasting condition, is $T_{b}$. Hypothermia not only decreases the thermal gradient, and thus the potential for heat loss to the environment, but the metabolic rate will fall below the basic rate, thus affording an additional economizing of energy through the $\mathrm{Q}_{10}$-effect. In torpor, the metabolic rate bears a direct exponential rela- tionship with $\mathrm{T}_{\mathrm{b}}$, with $\mathrm{Q}_{10}$-values of $1.5-5.6$ (mostly 4.1-4.3) being recorded for small hummingbirds (Lasiewski 1964; Lasiewski \& Lasiewski 1967; Hainsworth \& Wolf 1970). These two effects together enable a considerable saving of energy to be made. In one of the latest studies published on the subject of nocturnal hypothermia, hummingbirds were found able, by the use of nocturnal hypothermia, to save as much as $75 \%$ of their energetic costs, compared with their energy consumption at normal body temperature (Krüger et al. 1982). This reduction of the metabolic rate by hypothermic hummingbirds is of the same order of magnitude as that previously found by Lasiewski (1963) and Lasiewski \& Lasiewski (1967).

Most of our information on nocturnal hypothermia in birds has come, so far, from the many studies made on hummingbirds and published during the past two decades. However, nocturnal hypothermia has been observed among adult birds belonging to several different orders. The published observations, up to 1982 , on hypothermia in birds are summarized in Table 1 . The review article by Dawson \& Hudson (1970) provided a valuable source of information. Further data were extracted from individual publications on that subject.

\section{Brief comments on Table 1}

Most of the bird species listed in the table are poikilothermic during the state of hypothermia/ torpor, in the sense that their body temperature finally differs from the ambient temperature by only $1-2^{\circ} \mathrm{C}$. It was long believed that during hypothermia and torpor a bird relinquished its homeothermic state and became poikilothermic, but it is now generally accepted that this is more a controlled condition during which the body temperature is precisely regulated.

Typical metabolic responses of homeothermic and torpid hummingbirds to $T_{a}$ are illustrated in Fig. 1 (from Wolf \& Hainsworth 1972). During exposure to an air temperature below the lower limit of the regulated body temperature during the state of torpor, oxygen consumption is increased in proportion to the temperature difference $\left(T_{b}-T_{a}\right)$ and in parallel to the regression for normothernic metabolism below the lower critical temperature. This pattern has previously been observed for only a few bird species. Hainsworth \& Wolf (1978) have pointed out that 


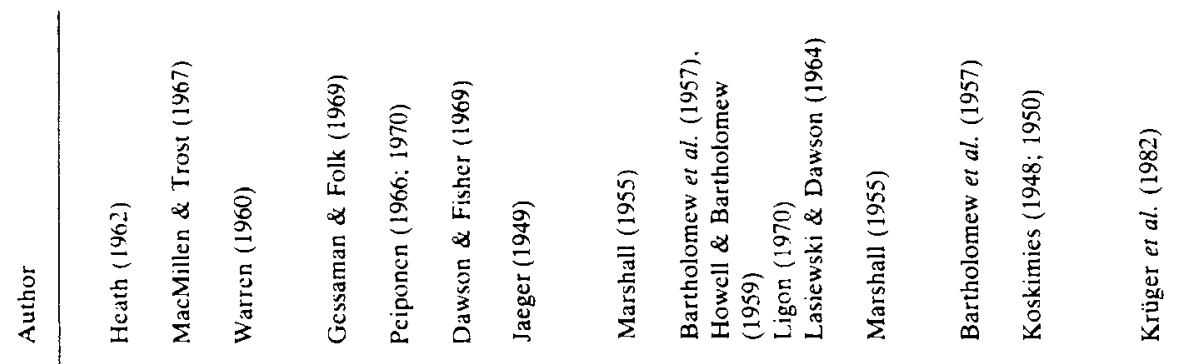

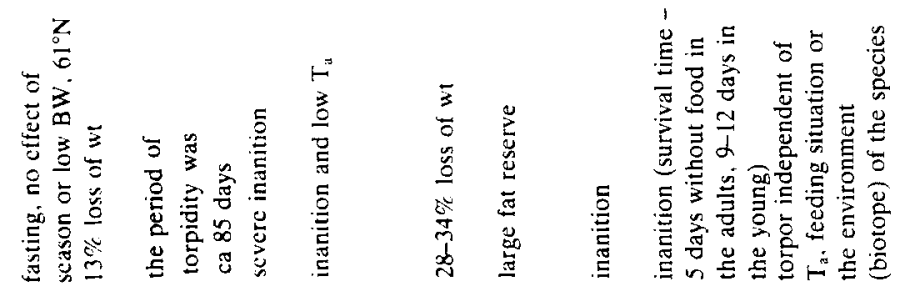

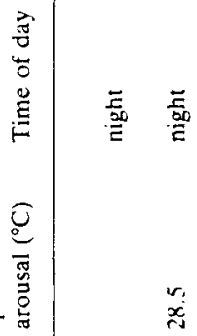

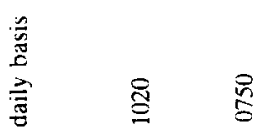

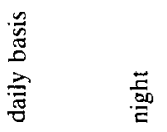

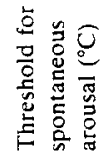

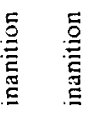

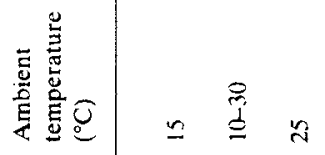

$\overline{7}$

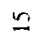

ภ

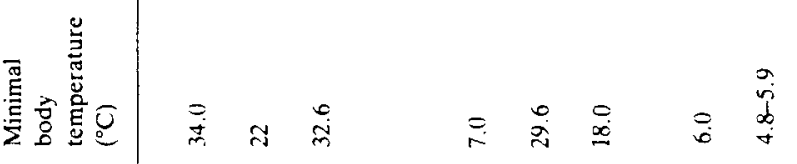

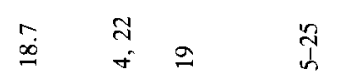

4 $\stackrel{n}{=} T$

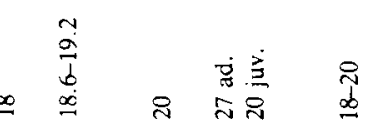

竞

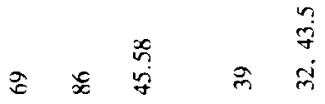

$n$

$\sqrt{3} \quad \dot{0}$

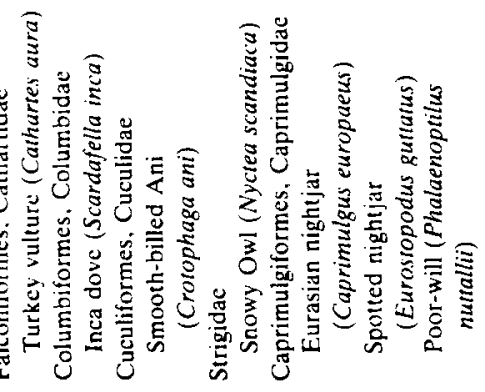

$\frac{0}{3}$

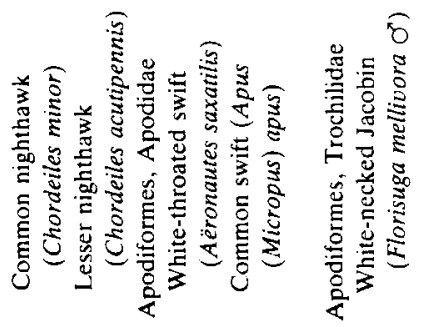




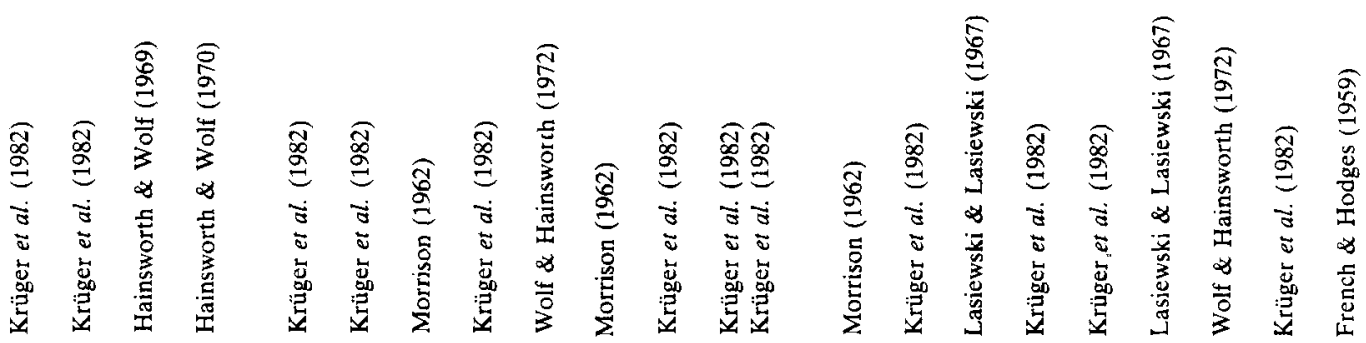

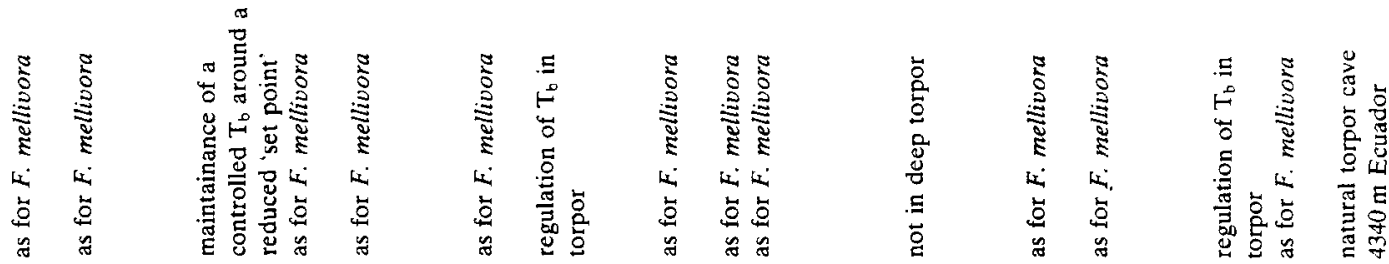

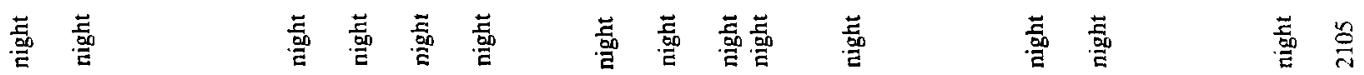

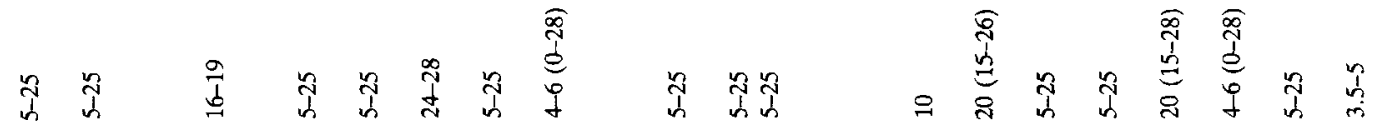

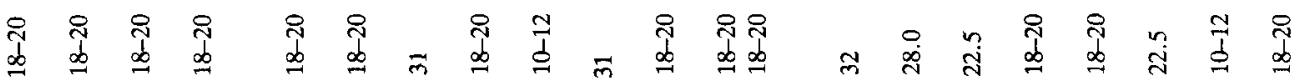

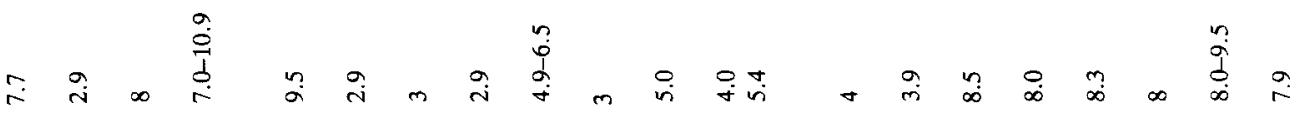

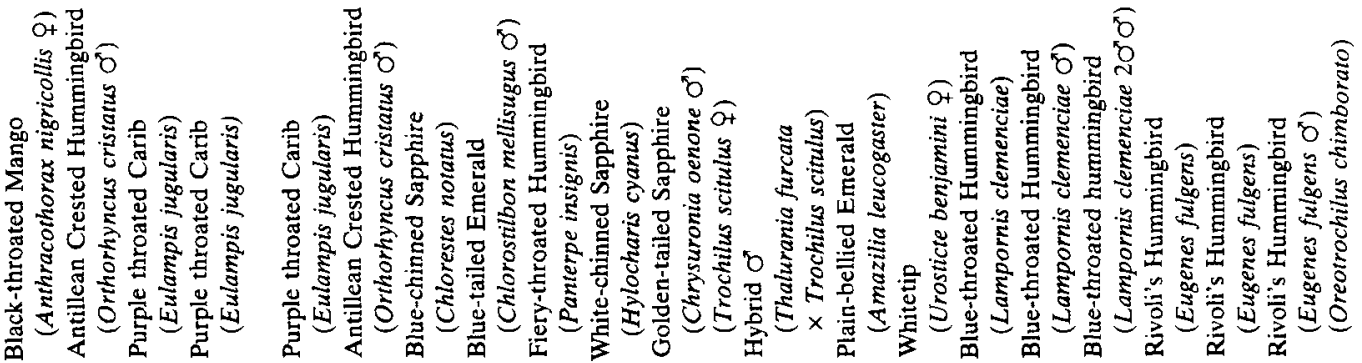




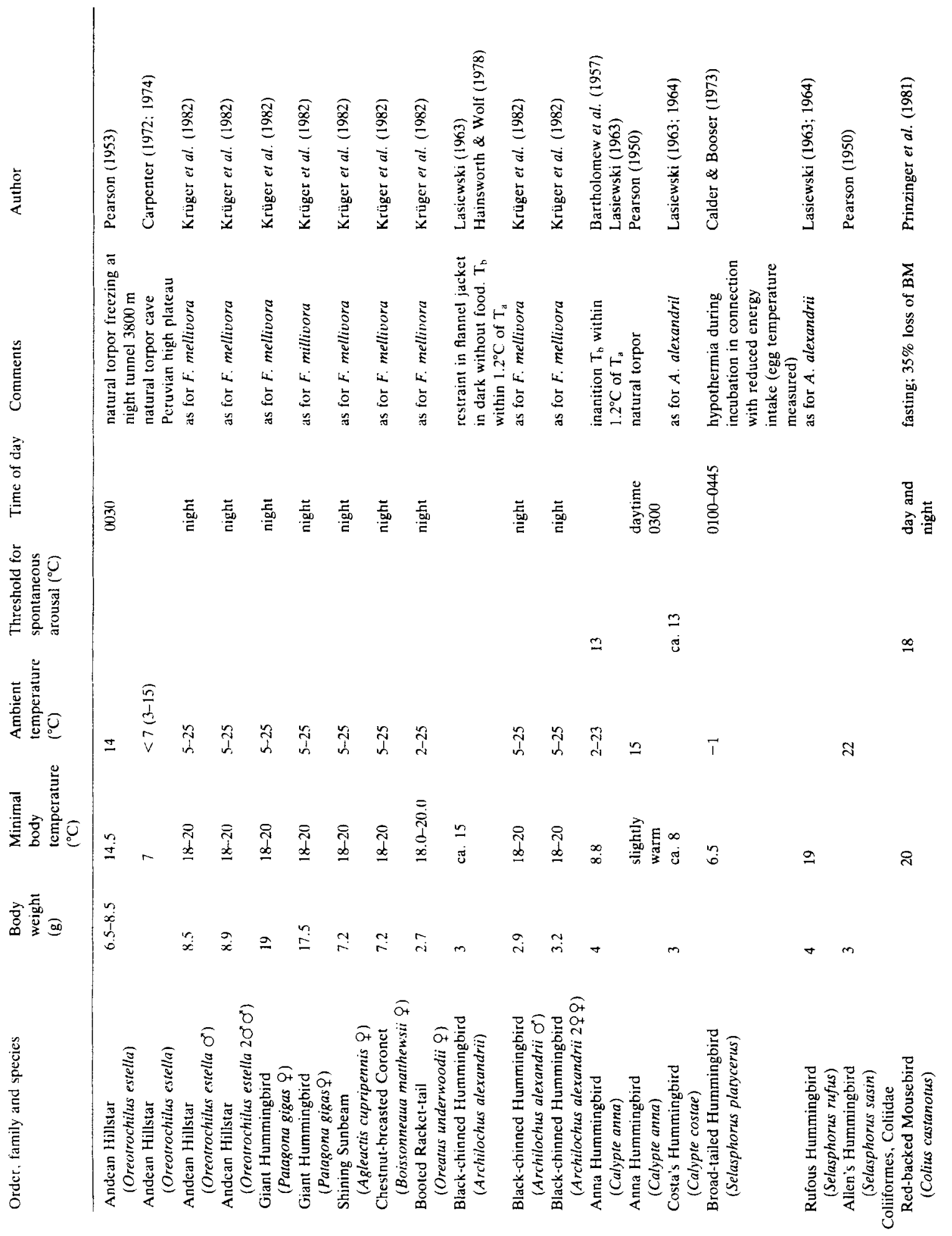




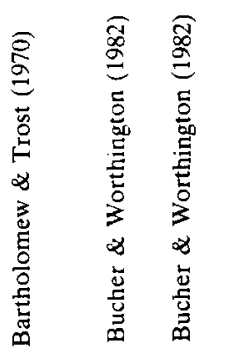

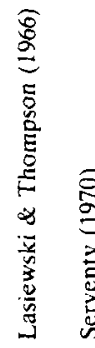

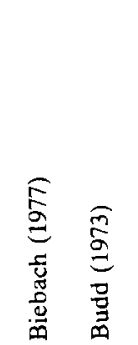

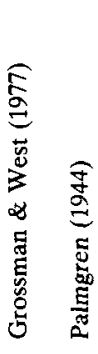

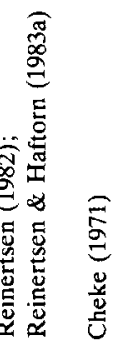

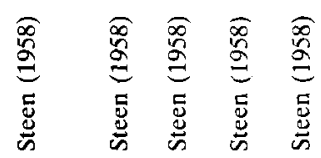

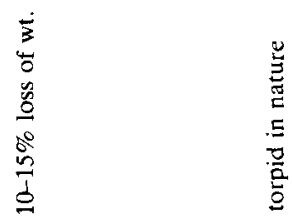
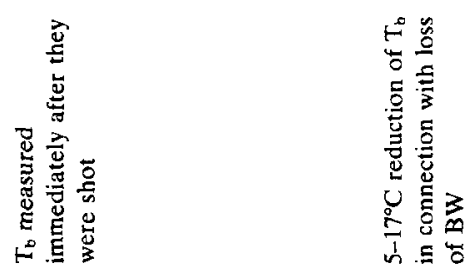

森

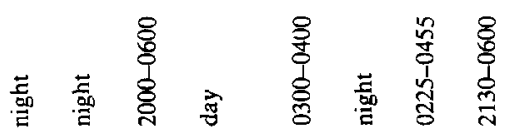

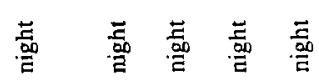

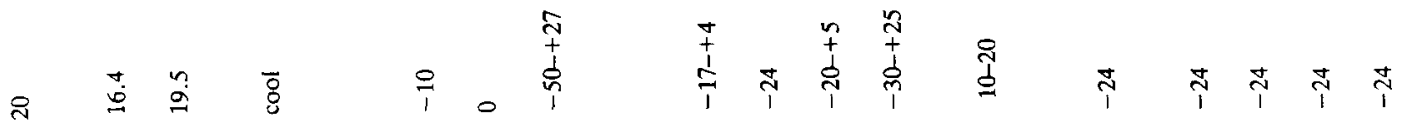

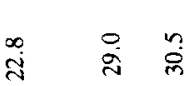

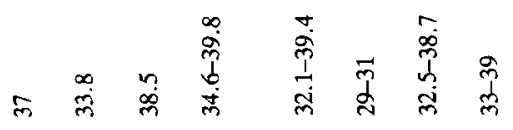

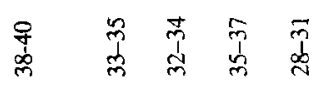

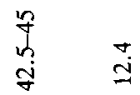
$\stackrel{ }{\stackrel{9}{ }}$

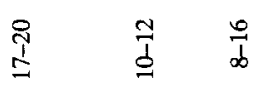

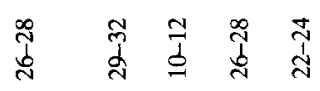

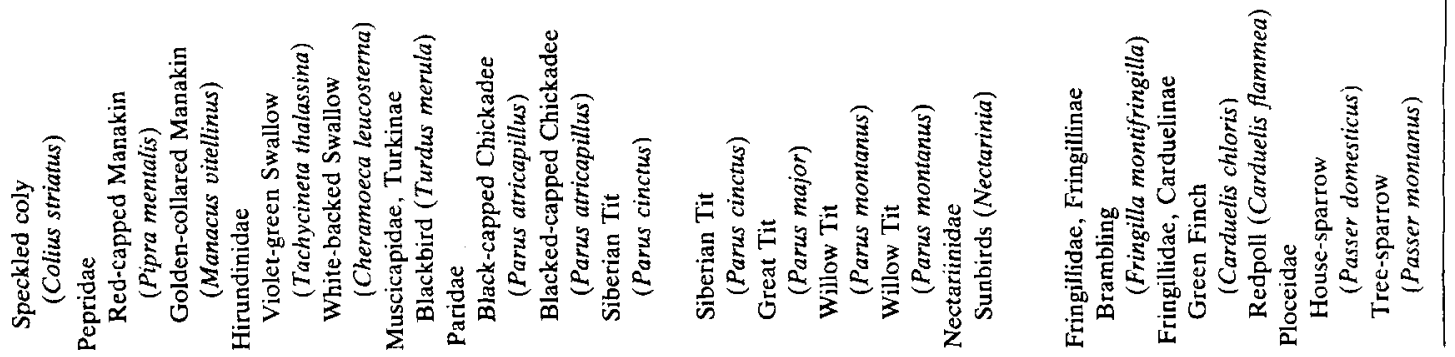




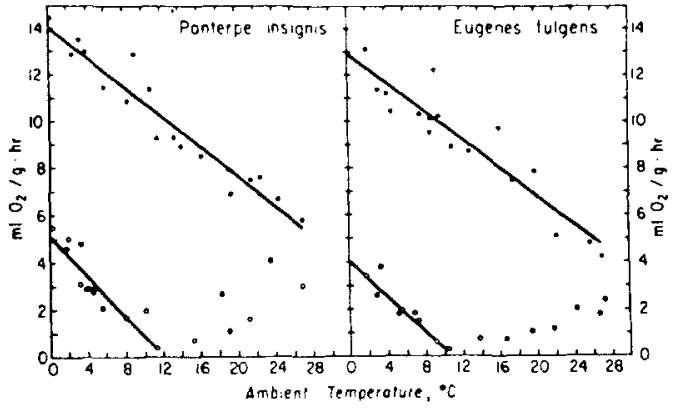

Fig. I. Relation between oxygen consumption and ambient temperature for Panterpe insignis and Eugenes fulgens. Solid circles are for resting birds; open circles signify birds in torpor. Each point represents a single determination. From Wolf \& Hainsworth (1972).

the lack of observation of this phenomenon in other studies of the same species may be attributed to methodological problems; i.e. body temperature regulation during a state of torpor, with its indication of precise physiological control, is probably a general characteristic of torpor in hummingbirds. This prediction was seemingly verified in a study made by Krüger et al. (1982), in which seventeen different species of hummingbirds and one hybrid were investigated. All the species showed torpor during the night-time, independent of the ambient temperature, feeding situation, or of the normal environment (biotope) of the particular species. During torpor, body temperature normally declined to the level of the ambient temperature, but never fell below 18 $20^{\circ} \mathrm{C}$. Consequently, a minimum energy consumption appears to occur at the lowest observed body temperature.

\section{Nocturnal hypothermia in small-sized northern birds}

When birds allow their body temperature to decline so far as to approach an ambient air temperature of $18-20^{\circ} \mathrm{C}$, this implies a truly dramatic lowering. However, an ambient temperature of this degree is not very extreme. Birds living in arctic and subarctic regions hardly ever experience such high ambient temperatures, and certainly not during the winter season. Only a few species of small birds (body-weight less than $30 \mathrm{~g}$ ) living in these regions have been studied with regard to hypothermia or torpor (Table 1).
These species include the green-finch Carduelis chloris, the brambling Fringilla montifringilla, the house-sparrow Passer domesticus, the tree-sparrow Passer montanus, the great tit Parus major, and the redpoll Achantis flammea (Steen 1958), the siberian tit Parus cinctus (Haftorn 1972; Palmgren 1944), the willow tit Parus montanus (Haftorn 1972; Reinertsen \& Haftorn 1983a), and the black-capped chickadee Parus atricapillus (Grossman \& West 1977). In addition to these studies an extensive study of the hypothermia of blackcapped chickadees living at $44^{\circ} \mathrm{N}$ is available (Budd 1973; Chaplin 1976).

None of the small birds studied exhibited such a profound degree of hypothermia as the torpor observed in hummingbirds and other species (Table 1). However, with the exception of the black-capped chickadees investigated by Grossman \& West (1977), they all let the body temperatures on cold winter nights fall below the normal nocturnal resting level.

Green-finch, brambling, house-sparrow, tree-sparrow, great tit and redpoll

Steen (1958) investigated six species of small birds: (a) in their natural acclimatization condition immediately after capture, and (b) after they had become acclimatized to an ambient temperature of $-10^{\circ} \mathrm{C}$ in a cold room for one week or more. The newly captured birds went into hypothermia during cold winter nights, with the body temperature falling to below $+30^{\circ} \mathrm{C}$ at ambient temperatures of between $-20^{\circ} \mathrm{C}$ and $+25^{\circ} \mathrm{C}$. The great tit and the tree-sparrow showed the most pronounced degree of hypothermia, with a $T_{b}$ value of $+30^{\circ} \mathrm{C}$. The degree of hypothermia was independent of how low the ambient temperature was. The energetic significance of hypothermia was a metabolic saving of 15 to $30 \%$ compared to their daytime metabolic rate. An additional metabolic saving of $10-30 \%$ was achieved by increasing their heat insulation during cold nights. All the birds then fluffed-up and placed their beaks in their shoulder feathers. Both these factors enabled the birds to survive throughout the cold nights with a metabolic rate of only 70 to $50 \%$ of the daytime level. In the morning the birds woke themselves up, a fact indicating that such a state of hypothermia is a normal reaction. When the same birds had become acclimatized to constant cold $\left(-10^{\circ} \mathrm{C}\right)$ and were supplied with plenty of food, none of them 
entered into a hypothermic state. It may well be, therefore, that the observed hypothermia was really an adaptation to a restricted food supply, under natural conditions. This would accord with various observations which indicate that hummingbirds do not necessarily at all times enter into torpor (Table 1 ) but only in connection with a state of inanition. Hainsworth et al. (1977) measured body mass just prior to the onset of dawn. His results indicated that torpor only occurred in association with a low body mass. He concluded that his results support the hypothesis that torpor only occurs when energy availability (in terms of the stored energy reserves) is restricted relative to energy expenditure. In Steen's study, however, the birds had at all times plenty of food available at an artificial feeding station, and were probably in good condition when tested immediately after being captured. Furthermore, they were not normally exposed to the air temperature prevailing at night outdoors, because various shelters were available to them offering favourable microclimates for roosting and enabling them to survive the winter nights. It was concluded that during the cold arctic night small birds utilize their available physical methods of thermoregulation to the utmost by fluffing-up and remaining motionless, and that they also get further protection from the cold by seeking shelter. If exposed to even colder weather, they increase their metabolic rate, lower their body temperature, and survive through the night by inducing a high degree of hypothermia. We thus see that such birds utilize hypothermia, together with the other mechanisms mentioned earlier, in order to save sufficient energy to survive through the night.

\section{Siberian tit}

The earliest-reported results on hypothermia in small arcric birds appeared in a study of the body temperatures and degree of body insulation of some Finnish birds during the wintertime (Palmgren 1944). Daytime measurements of the $T_{b}$ values of three Siberian tits gave values which lay between $34.6^{\circ}$ and $39.8^{\circ} \mathrm{C}$. The measurements were made immediately after the birds had been shot on cold days. Out of all the species of birds investigated, including the willow tit, only the Siberian tit exhibited hypothermia. Compared with the coal tit (Parus ater) and the marsh tit ( $P$. palustris), the two species of tits ranging furthest north, the Siberian tit and the willow tit, showed the best degree of insulation expressed in terms of weight of their feathers as a percentage of their body weight. Hypothermia, together with good body insulation, should make the Siberian tit well-adapted to the extreme cold of the Arctic. Udvardy (1955) measured the body temperatures of Siberian tits and of some closely-related species from arctic and subarctic localities in Northern Europe. No state of hypothermia was recorded for the Siberian tits, and there was no significant difference between the body temperatures of the Siberian tits and those of the other species of Parids studied in the experiments. Thus, no verification of the previously-reported thermal adaptation of the Siberian tit to the arctic winter was obtained, at least not for the daytime conditions. This discrepancy in the results obtained may be due to the use of different techniques for measuring body temperature in the two studies.

Night-time measurements of the body temperature of the Siberian tit were made by Haftorn (1972) in Finnmark, northern Norway $\left(69^{\circ} \mathrm{N}\right)$. The values recorded for eight individual birds ranged from $32.1^{\circ}$ to $38^{\circ} \mathrm{C}$. Furthermore, the hypothermic body temperature was found to be correlated with the ambient temperature. Daytime measurements of the body temperatures of these same eight individuals gave no indication of hypothermia, the recorded values being between $40.7^{\circ}$ and $42.1^{\circ} \mathrm{C}$ (mean $40.99^{\circ} \pm \mathrm{SD}$ $0.85^{\circ} \mathrm{C}$ ). These results are consistent with those obtained by Udvardy (1955).

\section{Willow tit and black-capped chickadee}

In addition to the Siberian tits, Haftorn (1972) also measured the body temperatures of twenty-five willow tits. They all showed nocturnal hypothermia, their body temperature values lying between $32.5^{\circ}$ and $38.7^{\circ} \mathrm{C}$. No correlation was found between the degree of hypothermia and the ambient temperature, such as was found in the case of the Siberian tit. Measurements of daytime body temperature gave values lying between $40.7^{\circ}$ and $42.6^{\circ} \mathrm{C}$ (mean $41.44^{\circ} \pm \mathrm{SD}$ $0.18^{\circ} \mathrm{C}$ ), which also correspond well with the values given by Udvardy (1955).

Neither Palmgren (1944), nor Haftorn (1972) measured the rate of oxygen consumption during hypothermia. They were thus unable to verify, or to quantify, the metabolic saving to be expected. In an extensive study of the physiology of the black-capped chickadee (a close relative 
of the willow tit) during hypothermia, birds exposed to an ambient temperature of $0^{\circ} \mathrm{C}$ had a metabolic rate $32-45 \%$ lower than that predicted for a $12 \mathrm{~g}$ homeotherm and a body temperature $10^{\circ} \mathrm{C}$ below the pre-experimental nocturnal body temperature (Chaplin 1976). As in the case of the Siberian tit (Haftorn 1972), the depth of hypothermia was found to depend on the ambient temperature, and furthermore. on the season of the year. The depression of the nocturnal body temperature during hypothermia was of the same order of magnitude as that found for the willow tit and the Siberian tit by Haftorn (1972).

No evidence of the same degree of nocturnal hypothermia observed in tits, in either Scandinavia or New York $\left(44^{\circ} \mathrm{N}\right)$, was observed in Alaskan black-capped chickadees (Grossman \& West 1977), although they were exposed to ambient temperatures down to $-50^{\circ} \mathrm{C}$. The birds used in the experiments were seasonally acclimatized to the winter photoperiod and air temperature (on average $-27^{\circ} \mathrm{C}$ ). It was concluded that the chickadees in Alaska display a better degree of body

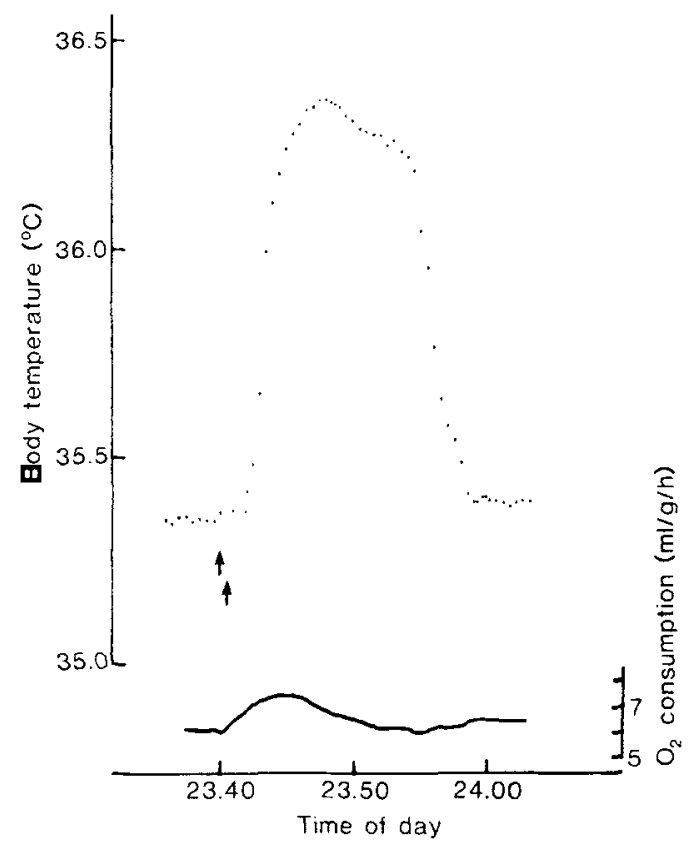

Fig. 2. Transient fluctuations in the nearly constant body temperature of a winter acclimatized willow tit as a result of a slight noise (silently opening and closing of the cabinet door. indicated by arrows). Ambient temperature was stable at $-10^{\circ} \mathrm{C}$. From Reinertsen \& Haftorn (1983a). insulation at $0^{\circ} \mathrm{C}$ than do the chickadees in New York (Budd 1973).

The findings from a study of nocturnal hypothermia and the metabolism of the willow tit, made at $63^{\circ} \mathrm{N}$ (Reinertsen \& Haftorn 1983a), agreed with the results obtained by Palmgren (1944), Steen (1958), Haftorn (1972), and Chaplin (1976) in that tits wintering in the far north utilize hypothermia to survive during cold winter nights. Energy expenditure was lowered by about $10 \%$, due to the lowering of the body temperature during hypothermia. The degree of hypothermia exhibited by the tits was dependent on the ambient temperature and also on the season of the year, just as Chaplin (1976) had found for the black-capped chickadee. Furthermore, the degree of hypothermia attained by the willow tits at $63^{\circ} \mathrm{N}$ was correlated with their body-weights at roosting time (Reinertsen 1982; Reinertsen \& Haftorn 1983b). This conflicts with the data obtained for the black-capped chickadee, whose hypothermic response showed no dependence on either the initial weight of the bird, or the amount of weight lost during exposure to low $T_{a}$ values (Chaplin 1974, 1976).

\section{Body temperature measurements}

A crucial question when judging whether or not cited observations represent true hypothermia, is the reliability of the body temperature measurements. Calder \& King (1974) pointed out that, because of the slight thermal inertia but very intense metabolism of small birds, handling and cloacal or proventricular probing for obtaining temperature measurements can induce a rapid rise from the temperature of the prehandling state. Continuous records of the intraperitoneal temperature of the willow tit, monitored telemetrically, clearly demonstrated that transient fluctuations in body temperature occur following various kinds of disturbance (Reinertsen 1980). Since the birds neither moved about nor changed their posture during the temperature fluctuations, it follows that changes in body temperature may occur without any visual indications being given. This, of course, is particularly important when the body temperature changes during sleep are being studied and the possibility of hypothermia exists (Fig. 2). Of all the results reviewed in the present article, the body temperature measurements of the willow tits living at $63^{\circ} \mathrm{N}$, cited above, are the only ones obtained with the aid of tel- 
Fig. 3. Circadian body temperature rhythm of a summer acclimatized willow tit. From Reinertsen \& Haftorn (1983a).

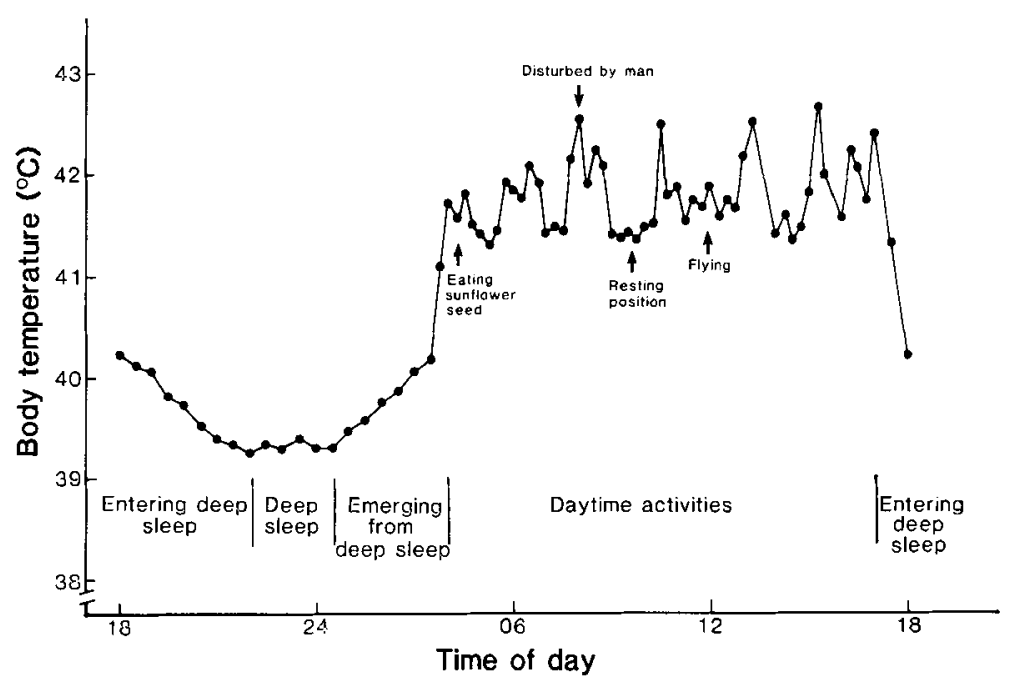

emetry equipment. Circadian body temperature rhythms of birds acclimatized to the locally prevailing conditions (Fig. 3) were studied throughout the year. On cold winter nights the recorded body temperatures were lower than those recorded during the summer at ambient temperatures in the thermoneutral zone, and the existence of nocturnal hypothermia, according to the definition given by Calder \& King (1974), was thereby established. Body temperature values obtained by conventional methods on hand-held birds during hypothermia are likely to be higher than the body temperature during the prehandling stage. Single recordings made in the evening or morning may be too high because the bird is in a state of entering into or emerging from hypothermia, respectively. Furthermore, whenever a bird is disturbed during sleep it is prone to arousal, and its body temperature will already have started to rise on that account when the recordings are made. Thus, the existence of a state of nocturnal hypothermia can now be considered to have been reliably established in the case of the following species: the willow tit (Haftorn 1972; Reinertsen \& Haftorn 1983a), the black-capped chickadee (Budd 1973; Chaplin 1976), the Siberian tit (Haftorn 1972), the green-finch, the brambling, the house-sparrow, the tree-sparrow, the great tit and the redpoll (Steen 1958). In addition, a record of daytime hypothermia exists for the Siberian tit (Palmgren 1944). Body temperatures of willow tits living at $63^{\circ} \mathrm{N}$, telemetrically measured, gave no indication of the existence of any correlation between the ambient temperature and the daytime body temperature.

\section{Induction of nocturnal hypothermia}

In most bird species hypothermia/torpor is only utilized in conjunction with a state of inanition (Table 1). Hummingbirds do not necessarily always enter into torpor (Calder \& Booser 1973; Howell \& Dawson 1954; Lasiewski 1963). Food deprivation was necessary to induce torpor in the laboratory (Lasiewski 1963), and in the field only during bad weather conditions that reduced the opportunities for foraging, did an incubating broad-tailed hummingbird Selasphorus platyceras enter into a state of torpor. These observations suggest that hummingbirds, with an adequate energy intake, are able to maintain nocturnal homeothermy, assuming that torpor results from a depletion of the energy reserves. Hainsworth et al. (1977) tried to verify this hypothesis. Body mass was used as an index of the stored energy reserves. Measurements of body mass made just prior to light onset and light offset indicated that torpor only occurred in association with low body mass values. There appeared to be a characteristic lower 'threshold' of energy storage, and for this particular species at least the magnitude of its stored energy reserves enabled one to predict if, and if so for how long, overnight torpor would set in. Dawson \& Hudson (1970) also pointed out the fact that in most of the experimental studies made so far, entry into a state of torpor was 


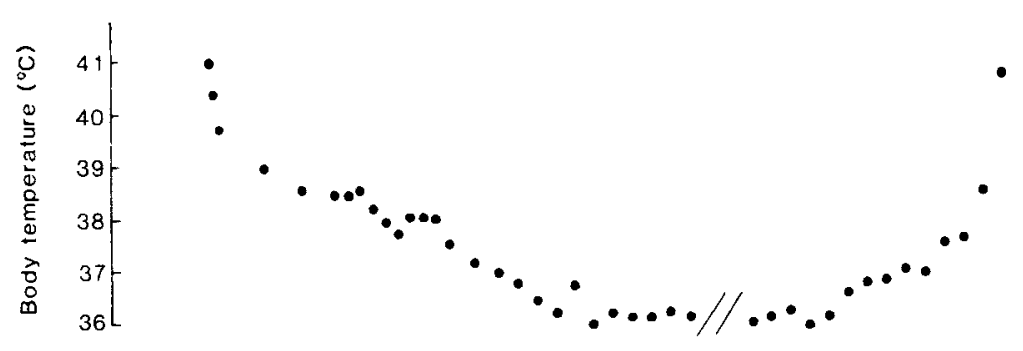

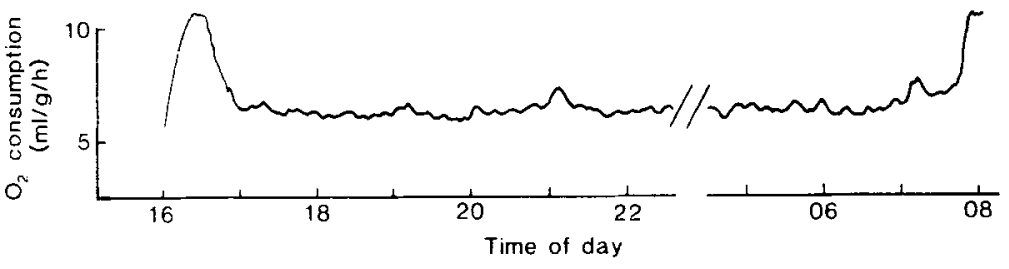

Fig. 4. The oxygen consumption and body temperature for a winter acclimatized willow tit entering into, during and emerging from the deep sleep phase at a stable ambient temperature of $0^{\circ} \mathrm{C}$. From Reinertsen \& Haftorn (1983a). associated with a moderate to severe depletion of the energy reserves. However, the dormant poor-will Phalaenoptilus nuttallii observed in nature by Jaeger (1949) was in fact relatively heavy $(52 \mathrm{~g})$, which suggests that it was in a good nutritional state. Marshall's discovery (1955) that captive lesser nighthawks Chordeiles acutipennis, after entering into a state of torpor, possessed significantly substantial fat reserves, also implies the existence of adequate reserves of energy. These results raise the question of whether or not, for goatsuckers and other truly heterothermic species, inanition is the only factor involved in the induction of dormancy. In nature, other stimuli may well exist, which should either act inde- pendently or serve to increase the sensitivity of such birds to any reduction of energy reserves. Perhaps the propensity of birds to become dormant changes seasonally, in a manner which is correlated with the photoperiod, the ambient temperature, or some other environmental factors. This last suggestion has been confirmed by subsequent studies made in the past decade. Studies of an Andean hummingbird (Carpenter 1974) showed that, in winter, nocturnal torpor occurred more frequently and lasted longer. Energy depletion did not seem to cause this annual torpor cycle, and he suggested the existence of a photoperiodically-controlled endogenous rhythm that enabled the birds automatically to conserve

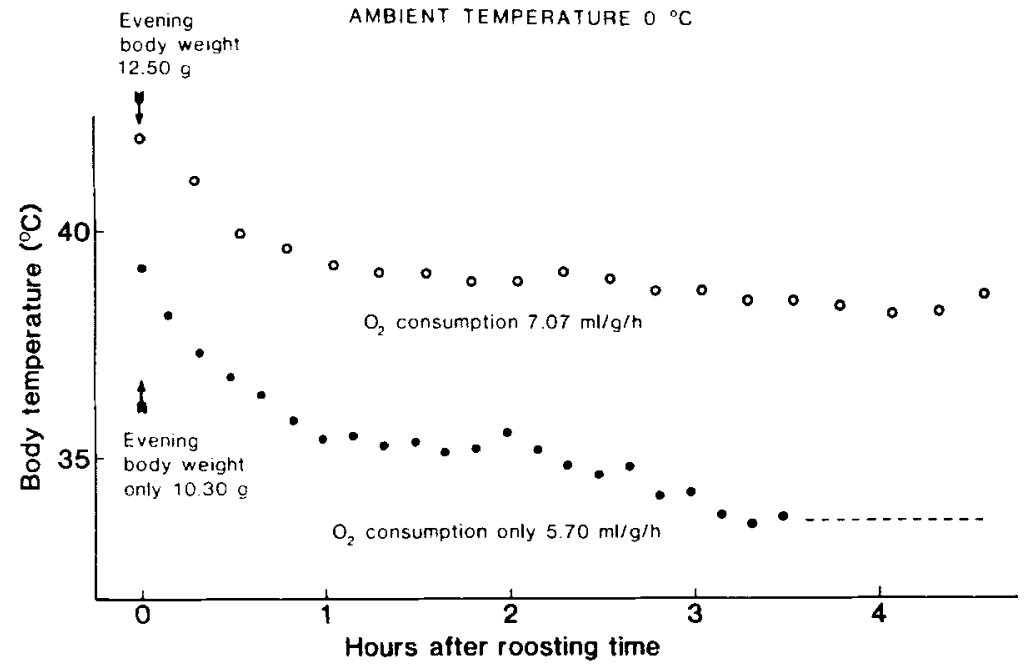

Fig. 5. The decline during the evening and final levelling-off of the body temperature of a winter acclimatized willow tit for two different body weights at roosting time. From Reinertsen \& Haftorn (1983b). 
their energy in the early evening hours for fulfilling eventual metabolic expenditure demands later on during the night in winter.

Such a seasonal effect was further demonstrated for the black-capped chickadee (Chaplin 1976) and for the willow tit (Reinertsen \& Haftorn 1983a). In both cases the maximum hypothermic response was observed in birds acclimatized to mid-winter conditions, whereas birds acclimatized to mid-summer conditions showed almost no response. A circannual cycle of hypothermia will be especially valuable to any organism living in a region subject to wide seasonal fluctuations in the ambient temperature. The demonstrated dependence of the hypothermic response to the season supports the hypothesis that it represents an important adaptation to the prevailing environmental conditions; the maximum hypothermic response of the willow tit was recorded during midwinter, the time of the year when the lowest ambient temperatures normally occur, food is scarce, and the enforced nocturnal fast lasts for about 18 hours. Furthermore, for both the black-capped chickadee and the willow tit, the depth of hypothermia achieved was significantly and linearly correlated with the ambient temperature. Among all the tit species studied, an additional correlation between body-weight at roosting time and the depth of hypothermia has been found only for the willow tit; if body-weight at roosting time was below normal, the nocturnal body temperature recorded was lower than that of a bird in good condition, in relation to level of hypothermia normally achieved at that season and ambient temperature. When inanition, or fasting, is necessary to induce hypothermia, the metabolism and body temperature fall gradually as body weight becomes depleted (Biebach 1977; Prinzinger et al. 1981). However, this is not so in the case of the willow tit, neither for those in good condition nor those with a low body weight. In both cases, the metabolic rate falls to a certain level at roosting time and is maintained at this level throughout the night, regardless of how much the energy reserves are depleted (Figs. 4 and 5) (Reinertsen \& Haftorn 1983a, b).

\section{Energetic significance}

The energetic significance of nocturnal hypothermia is highly dependent on just how great a depression of body temperature is acceptable, on the duration of the hypothermic state, and on the cost of rewarming

\section{$T_{\mathrm{b}}-T_{\mathrm{a}}$ gradient}

If the body temperature value can be allowed to fall to that of the ambient temperature, then heat loss from the body will be minimal. The nightjar Caprimulgus europaeus, the poor-will and a couple of Hummingbird species can tolerate body temperatures below $10^{\circ} \mathrm{C}$. For most bird species, however, metabolic heat production rises when the body temperature has fallen to about $20^{\circ} \mathrm{C}$, in order to prevent the body temperature from falling below a level at which spontaneous arousal will no longer be possible. In small-sized arctic and subarctic birds body temperatures below $30^{\circ} \mathrm{C}$ have not been recorded during hypothermia. This implies that even at the maximum degree of hypothermia, a considerable difference still exists between the body temperature and the prevailing low ambient temperature; at $-30^{\circ} \mathrm{C}$ the willow tit can tolerate a nocturnal body temperature of $+32^{\circ} \mathrm{C}$; this represents only a $15 \%$ reduction of the temperature gradient between body core and environment, but even such a comparatively small reduction in body temperature implies a considerable reduction in the nightly expenditure of energy. In the parid species studied by Steen (1958) for newly-caught birds, the metabolic saving achieved by nocturnal hypothermia amounted to $15-30 \%$ compared to the metabolic rate in daytime. Black-capped chickadees living in temperate regions achieve an even higher degree of energy saving, their metabolic rate being $32-45 \%$ lower than the predicted value for a homeothermic bird of $12 \mathrm{~g}$ body-weight and a body temperature $10^{\circ} \mathrm{C}$ below the pre-experimental nocturnal body temperature (Budd 1973; Chaplin 1974). No metabolic saving due to nocturnal hypothermia was found in the case of the Alaskan black-capped chickadees, even though they were studied at ambient temperatures down to $-50^{\circ} \mathrm{C}$. At $0^{\circ} \mathrm{C}$ the weight-specific nocturnal metabolism was about $8 \mathrm{ml} \mathrm{O}_{2} \cdot \mathrm{g}^{-1} \mathrm{~h}^{-1}$, compared to about $7.5 \mathrm{ml} \mathrm{O}_{2} \cdot \mathrm{g}^{-1} \mathrm{~h}^{-1}$ for birds living in the temperate region. Although the slope of the regression line for oxygen comsumption indicated a gradual decrease of $T_{b}$ with decreasing $T_{a}$, no hypothermic body temperature was recorded. The lowest metabolic rate value, at an ambient temperature of $0^{\circ} \mathrm{C}$, has been reported for the willow tit. Its nocturnal oxygen consumption during hypothermia was less than $6 \mathrm{ml} \mathrm{O}_{2} \cdot \mathrm{g}^{-1} \mathrm{~h}^{-1}$, and 
its body temperature about $36^{\circ} \mathrm{C}$. This was calculated to represent about a $10 \%$ lowering of energy expenditure compared to the estimated value for the non-hypothermic nocturnal metabolic rate of a bird with the same plumage conductance; the savings accomplished by a lowering of the body temperature from the daytime level of $41.3^{\circ} \mathrm{C}$ to the nocturnal $T_{b}$ in the thermoneutral zone have not been taken into account.

The apparent differences of the energy savings reported are due to the different methods used for estimating the savings accomplished by nocturnal hypothermia. When the nocturnal hypothermic metabolic rate is compared with daytime metabolic rate, the savings will appear greater than when the method of comparison described for the willow tit is utilized.

\section{The cost of rewarming}

Grossman \& West (1977) claimed that the Alaskan chickadee was unable to tolerate a state of hypothermia because of the potentially high difference between its body temperature and the low ambient temperatures; during rewarming, such a large demand would be made on the energy reserves of the body that these might not be readily mobilizable if the bird was in a deep hypothermic state. Observations of nocturnal hypothermia in the willow tit have also shown that the rewarming process in the morning is especially demanding. One willow tit acclimatized to the winter conditions was in such a poor condition, expressed in terms of its body weight at roosting time, that it was only able to rewarm its body core from the hypothermic state to $38^{\circ} \mathrm{C}$, and unable to increase its metabolic rate further in order to rewarm up to the normal daytime body temperature value of $41.3^{\circ} \mathrm{C}$. However, all the other experimental birds were able to rewarm sufficiently to achieve their normal body temperature value again in the morning (Reinertsen \& Haftorn 1983a). None of the chickadees in Chaplin's (1976) laboratory study were able to re-attain their normal diurnal body temperature. This may indicate that the birds studied were not in a very good condition. Furthermore, this may explain the comparatively deep degree of hypothermia attained at relatively moderate ambient winter temperatures. If this is the case, the black-capped chickadee too may be able to regulate its degree of hypothermia according to the prevailing state of its energy reserves. This may also explain why the above-mentioned Alaskan chickadees did not enter into a state of hypothermia; on average, these birds weighed about $1 \mathrm{~g}$ more than the birds in Chaplin's study, and this $1 \mathrm{~g}$ may have represented a sufficient reserve of energy to have enabled the birds to survive the night without utilizing hypothermia. The process of spontaneous arousal from torpor involves a dramatic rise in oxygen consumption, which appears to depend primarily on vigorous shivering. If sufficient energy reserves are not readily available to allow such shivering activity to take place, the bird will eventually die. The rate of warming in birds actively arousing from a state of hypothermia appears to be inversely related to their body weight. This means that hypothermia will be too costly a mechanism for a large-sized animal at low ambient temperatures. From this point of view it would be especially economical for the small northern birds to become hypothermic for short nocturnal periods.

\section{Duration of the hypothermic state}

Single observations of body temperature made during the night and recordings of the metabolic rate during hypothermia made over short periods of time, cannot properly indicate the duration and depth of hypothermia. When the body temperature and metabolic rate of undisturbed willow tits were recorded continuously throughout the night, it was found (Reinertsen \& Haftorn 1983a) that although the body temperature did not reach its lowest level before sometime between 2100 and 2200 hours, the level of the hypothermic metabolism was fixed within half an hour after roosting time and remained at this level throughout the night (Fig. 4). At a constant ambient temperature, constant conductance, and constant metabolic rate, the value at which the body temperature will level off in the evening is thus pre-set in the afternoon. It would therefore seem that, depending on the magnitude of the energy reserves (in terms of stored fat), the ambient temperature, and the length of the night, at roosting time the willow tit adopts the particular metabolic rate that it can afford to maintain constantly throughout the night.

\section{Conclusion}

Due to body mass-related effects on heat loss, the rate of energy expenditure per gram body 
weight at a constant ambient temperature increases with decreasing body mass (May 1976; Schmidt-Nielsen 1975). This mass-related metabolic rate, together with a mass-related digestive capacity, make it difficult for small-sized species of birds to build up a sufficient store of energy for the non-feeding periods. However, if we consider the animal as a biological entity, rather than from a per gram body-weight perspective alone, it is advantageous being small, because a small bird requires less food, in absolute terms, than a large one does. Their inability to endure fasts of long duration is probably the greatest problem faced by small-sized birds during the winter nights in the Arctic. Like hummingbirds, tits cannot survive for even a single day without food. In the studies reviewed in this paper the tits utilized several energy-saving mechanisms, nocturnal hypothermia among them, and, just because of their small body mass, hypothermia is an especially suitable mechanism for tits, as it does not take long to rewarm such a small body mass in the morning. It remains to be seen whether or not nocturnal hypothermia is a mechanism utilized by other small-sized species of birds living in arctic and subarctic regions, in addition to those cited in this review. For those species in which this phenomenon has been demonstrated, nocturnal hypothermia is utilized together with other thermoregulatory responses, and on a daily basis not only in emergency situations. For none of these small northern birds is inanition necessary for the induction of a state of hypothermia. This perhaps represents an important distinction between the state of nocturnal hypothermia of birds living at high and at low latitudes.

Acknowledgements. - I thank S. Haftorn for valuable comments on this manuscript, P. A. Tallantire for improving the language, I. Harder and G. Herjuaune for preparing the manuscript. The study was supported by the Norwegian Research Council for Science and the Humanities.

\section{References}

Aschoff. J. \& Pohl, H. 1970a: Der Ruheumsatz von Vögeln als Funktion der Tageszeit und der Körpergrösse. J. Ornithol. $111,38-47$.

Aschoff, J. \& Pohl, H. 1970b: Rhythmic variations in energy metabolism. Fed. Proc. Am. Soc. Exp. Biol. 29, 1541-1552.

Bartholomew, G. A. \& Trost, C. H. 1970: Temperature regulation in the speckled mousebird (Colius striatus). Condor $72,141-146$.

Bartholomew, G. A., Howell, T. R. \& Cade T. J. 1957: Torpidity in the White-throated swift, Anna hummingbird and Poor-will. Condor 59, 145-155.

Biebach, H. 1977: Reduktion des Energiestoffwechsels und der
Körpertemperatur hungernder Amseln (Turdus merula). $J$. Ornithol. 118, 294-300.

Binkley, S., Kluth, E. \& Menaker M. 1971: Pineal function in sparrows; circadian rhythms and body temperature. Science 174, 311-314

Bucher, T. \& Worthington, A. 1982: Nocturnal hypothermia and oxygen consumption in Manakins. Condor 84, 327-331.

Budd, S. M. 1973: Thermoregulation, Bioenergetics and Endocrinology of Cold Acclimatization of Black-capped Chickadees (Parus atricapillus). Doctoral thesis, Cornell University, Ithaca, New York.

Brown, J. H. \& Bartholomew, G. A. 1969:Periodicity and energetics of torpor in the kangaroo mouse (Micridipodops pallidus). Ecology 50, 705-709.

Calder, W. A. \& Booser, J. 1973: Hypothermia of Broad-tailed Hummingbirds during incubation in nature with ecological correlations. Science 180, 751-753.

Calder, W. A. \& King, J. R. 1974: Thermal and caloric relations of birds. In Farner, D. S. \& King, J. R. (eds.): A vian Biology 4, 259-413. New York and London, Academic Press.

Carpenter, L. 1972: Torpidity in the Andean Hillstar Hummingbird (Oretrocilus estella estella). Cooper Ornithol. Soc. Abstr. Ann. Meet. 43, 28.

Carpenter, F. L. 1974: Torpor in an Andean hummingbird: Its ecological significance. Science 183, 545-547.

Chaplin, S. B. 1974: Daily energetics of the black-capped chickadee (Parus atricapillus) in winter. J. Comp. Physiol. 89, 321-330.

Chaplin, S. B. 1976: The physiology of hypothermia in the black-capped chickadee (Parus atricapillus). J. Comp. Physiol. 112B, 335-344.

Cheke, R. A. 1971: Temperature rhythms in African montane sunbirds. Ibis 113, 500-506.

Dawson, W. R. \& Fisher, C. D. 1969: Responses to temperature in the Spotted nightjar. Condor 71, 49-53.

Dawson, W. R. \& Hudson, J. W. 1970: Birds. In.Whittow, G. C. (ed.): Invertebrates and Nonmammalian Vertebrates (Comparative Physiology of Thermoregualtion, 1), 223-310. Academic Press, New York.

Fisher, K. C. \& Mannery, J. F. 1967: Water and electrolyte metabolism in heterotherms. In Fisher, K. C., Dawe, A. R., Lyman, C. P., Schönbaum, E. \& South, F. E. (eds.). Mammalian Hibernation III, 235-279. American Elsevier, New York.

French, A. R. 1976: Selection of high temperatures for hibernation by the pocket mouse (Perognathus longimembris). Ecological advantages and energetic consequences. Ecology 57, 185-191.

French, N. R. \& Hodges, R. W. 1959: Torpidity in cave roosting hummingbirds. Condor 61, 223.

Gessaman, J. A. \& Folk Jr., G. E. 1969: Body temperature and thermal conductance of the Snowy Owl. Physiologist 12 , 234

Grossman, A. F. \& West, G. C. 1977: Metabolic rate and temperature regulation of winter acclimatized black-capped chickadees (Parus atricapillus) in interior Alaska. Ornis Scand. 8, 127-138.

Haftorn, S. 1972: Hypothermia of Tits in the arctic winter. Ornis Scand. 3, 153-166.

Hainsworth, F. R. \& Wolf, L. L. 1969: Resting, torpid and flight metabolism of the hummingbird. Am. Zoologist 9 , 1100-1101.

Hainsworth, F. R. \& Wolf, L. L. 1970: Regulation of oxygen consumption and body temperature during torpor in a hummingbird (Eulampis jugularis). Science 168, 368-369. 
Hainsworth, F.R. \& Wolf, L. L. 1978: Regulation of metabolism during torpor in 'temperate' zone hummingbirds. Auk 95. 197-199.

Hainsworth. F. R. \& Wolf. L. L. 1978: The economics of regulation and torpor. In Wang. L. C. H. \& Hudson, J. W. (eds.). Strategies in Cold: Natural Torpidin and Thermogenesis, 147-184. Academic Press, New York.

Hainsworth, F. R. Collins, B. G. \& Wolf. L. L. 1977: The function of torpor in hummingbirds. Physiol Zool. 50. 215-222.

Heath. J. E. 1962: Temperature fluctuation in the Turkey Vulture. Condor 64. 234-235.

Hill, R. H. Beaver. D. L. \& Veghte. J. H. 1980: Body surface temperature and thermoregulation in the Black-capped Chickadee (Parus atricapillus). Physiol. Zool. 53. 305-321.

Hissa, R. \& Palogangas. R. 1970: Thermoregulation in the Titmouse (Parus major L). Comp. Biochem. Physiol. 33. 941-953.

Howell. T. R. \& Bartholomew, G. A. 1959: Further experiments on torpidity in the Poor-will. Condor 61. 180-185.

Howell, T. R. \& Dawson. R. 1954: Nest temperatures and attentiveness in the Anna hummingbird. Condor 56.93-97.

Irving, L. 1960: Birds of Anaktuvuk Pass. Kobuk and Old Crow: a study in arctic adaptation.U.S. Natl Museum. Bull. Smthsonian Institution, Washington D.C. 217. 1-409.

Jaeger. E. C. 1948: Does the Poor-will 'hibernate"? Condor 50. 45-46.

Jaeger. E. C. 1949; Further observations on the hibernation of the Poor-will. Condor 51, 105-109.

Kleiber, M. 1961: The Fire of Life. Wilcy. New York

Kleiber. M. 1972: Body size, conductance for animal heat flow: and Newton's Law of cooling. J. Theor. Biol. 37, 139-150.

Koskimies. J 1948: On temperature regulation and metabolism in the Swift (Micropus a. apus L.) during fasting. Experientia 7. 274-276.

Koskimies. J. 1950: The life of the Swift (Micropus apus (L.)) in relation to the weather. Ann. Acad. Sci. Fennicae: Ser A IV 15.1-151.

Krugcr. K., Prinzinger. P. \& Schumann. K. L. 1982: Torpor and metabolism in hummingbirds. Comp. Biochem. Physiol. 73A. 679-689

Lasiewski. R. C. 1963; Oxygen consumption of torpid. resting. active and fying hummingbirds. Physiol. Zool. 36. 122-140.

Lasiewski. R. C. 1964: Body temperature, heart and breathing rate. and evaporative water loss in hummingbirds. Physiol. Zool. 37, 212-223.

Lasiewski. R. C. \& Dawson. W. R. 1964: Physiological responses to temperature in the common nighthawk. Condor $66,477-490$

Lasiewki. R. C. \& Lasiewski. R. J. 1967: Physiological responses of the Blue-throated and Rivoli's hummingbirds. Auk 84, 34-48.

Lasiewski. R. C. \& Thompson. H. J. 1966: Field observation of torpidity in the Violet-green Swallow. Condor $68.102-$ 103.

Lasiewski. R. C.. Weathers, W. W. \& Bernstein. M. H. 1967: Physiological responses of the Giant Hummingbird (Patagona gigas). Comp. Biochem. Physiol. 23. 797-813.

Ligon, J. D. 1970: Still more responses of the Poor Will to low temperatures. Condor 72, 496-497.

MacMillen. R. E. \& Trost. C. H. 1967: Nocturnal hypothermia in the Inca dove (Scardafella incat. Comp. Biochem. Physiol. 23, 243-253.

Marshall. J. $\Upsilon$. 1955: Hibernation in captive goatsuckers. Condor 57. 129-134.
May. M. L. 1976: Warming rates as a function of body size in periodic endotherms. J. Comp. Physiol. 111, 55-70.

Morrison, P. 1962: Modification of body temperature by activity in Brazilian hummingbirds. Condor 64, 315-323.

Palmgren. P. 1944: Körpertemperatur und Wärmeschutz bei einigen finnischen Vögeln. Ornis Fennica 21, 92-104.

Pearson. O. P. 1950: The metabolism of hummingbirds. Condor 52. 145-152.

Pearson, O. P. 1953: Use of caves by hummingbirds and other species at high latitudes in Peru. Condor 55, 17-20.

Pearson. O. P. 1960: Torpidity in birds. In Lyman, C. P. \& Dawe. A. E. (eds.): Mammalian hibernation, symposium. Bull. Mus. Comp. Zool. 124. 93-103.

Peiponen. V. A. 1966: The diurnal heterothermy of the nightjar (Caprimulgus europaeus L.). Ann. Acad. Sci. Fennicae Ser. A IV $101,1-35$.

Peiponen. V. A. 1970: Body temperature fluctuations in the Nightjar (Caprimulgus e. europaeus L.) in light conditions of Southern Finland. Ann. Zool. Fennici 7, 239-250.

Prinzinger. R., Göppel, R., Lorenz, A. \& Kulzer, E. 1981: Body temperature and metabolism in the red-backed mousebird (Colius castanotus) during fasting and torpor. Comp. Biochem. Physiol. 69A, 689-692.

Reinertsen. R. E. 1980: A telemetry study on deep body temperature of the Willow Tit (Parus montanus). Acta Physiol. Scand. $108,32 \mathrm{~A}$

Reinertscn. R. E. 1982a: Radio telemetry measurements of deep body temperature of small birds. Ornis Scand. 13, $11-16$.

Reinertsen, R. E. 1982b: The effect of body mass on $\mathrm{O}_{2}$ consumption rate and nocturnal hypothermia in the Willow Tit (Parus montanus). Acta Physiol. Scand. Supplementum 508. 46 .

Reinertsen, R. E. \& Haftorn. S. 1983a: Nocturnal hypothermia and metabolism in the Willow Tit (Parus montanus) at $63^{\circ} \mathrm{N}$. J. Comp. Physiol. (in press).

Reinertsen, R. E. \& Haftorn, S. 1983b: The effect of shorttime fasting on the metabolism and nocturnal hypothermia in the Willow Tit (Parus montanus). J. Comp. Physiol. 151, $109-118$.

Schmidt-Niclsen. K. 1975: Animal Physiology. Cambridge Lniv. Press, London and New York.

Scholander. P. F. Hock. R., Walters, V., Johnson, F. \& Irving, L. 1950: Heat regulation in some arctic and tropical mammals and birds. Biol. Bull. $99,237-258$.

Serventy. D. L. 1970: Torpidity in the White-backed Swallow. Emu $70.27-28$

Steen. J. B. 1958: Climatic adaption in some small northern birds. Ecology 39, 625-629.

Tucker, V. A. 1966: Diurnal torpor and its relation to food consumption and weight changes in the California pocket mouse (Perognathus californicus). Ecology 47, 245-252.

Turcek. F. J. 1966: On plumage quantity in birds. Ekol. Polksa A14. 617-633.

Ldvardy. M. D. F. 1955: Body temperature of parids in the arctic winter. Ornis Fennica 32, 101-107.

Veghte, I. H. \& Herreid, C. F. 1965: Radiometric determination of feather insulation and mctabolism of arctic birds. Physiol. Zool. 38. 267-275.

Warren. J. W. 1960: Temperature fluctuation in the Smoothbilled ani. Condor 62, 293-294.

Wolf. L. L. \& Hainsworth, F. R. 1972: Environmental influence on regulated body temperature in torpid hummingbirds. Comp. Biochem. Physiol. 41, 167-173. 